\title{
Prisión preventiva y error judicial probatorio
}

\author{
Jaime Andrés Manríquez Oyaneder*
}

\begin{abstract}
RESUMEN
El artículo se aboca a la tarea de analizar las dificultades probatorias en torno al error judicial contenido en el artículo $19 \mathrm{~N}^{\circ} 7$ letra i) de la Constitución Política de la República, circunscribiéndolo al ámbito cautelar penal, particularmente a la prisión preventiva.

El presente estudio postula la incoherencia sistémica de detectar el error probatorio en un sistema cautelar penal que no lo reconoce, pues carece de estándar. Para ello se utiliza como bilo conductor la sentencia de la Excelentísima Corte Suprema, causa rol 1.579-2015, único fallo que a la fecha ha acogido una solicitud de error judicial respecto del sometimiento de una persona a prisión preventiva.
\end{abstract}

Prisión preventiva - razonamiento probatorio - error judicial

\section{Pre-trial detention and evidentiary miscarriage of justice}

\begin{abstract}
The article aims to analyze the evidentiary difficulties of the miscarriage of justice contained in the article $19 \mathrm{~N}^{\circ} 7$ letter i) of the Political Constitution of the Republic by dealing exclusively with preventive criminal law, more specifically, pre-trial detention.

The following study postulates the systemic incoherence of detecting the evidentiary error in a criminal justice system that does not recognize it due to its lack of standard. To this effect, Case $N^{o}$ 1.579-2015, the Excellency Supreme Court sentence is used as a guiding thread for it remains the only verdict thus far that has allowed a miscarriage of justice appeal regarding a pre-trial detention.
\end{abstract}

Pre-trial detention - evidentiary reasoning - miscarriage of justice

* Licenciado en Ciencias Jurídicas, Universidad Católica de Temuco. Magíster en Derecho con mención en Derecho Privado, Universidad de Chile. Correo electrónico: jmanri.oyanader@gmail.com

Artículo recibido el 28.10.2019 y aceptado para su publicación el 5.5.2020. 
"Lo que nosotros observamos no es la naturaleza en sí, sino la naturaleza expuesta a nuestro método de interrogación”.

Heinsenberg Werner, 1958, p. 58.

\section{INTRODUCCIÓN}

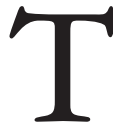
wining nos invita a tomarnos en serio las cuestiones relativas a la prueba de los hechos como parte integrante de la comprensión del derecho ${ }^{1}$. En este contexto, es importante dejar constancia de que la formación jurídica hasta hace un tiempo en nuestro medio se situaba distante del mundo de los hechos, por lo que el estudio de la realidad parecía quedar supeditada a una cuestión de mera práctica forense.

La investigación se centra en el estudio del razonamiento probatorio cautelar-penal, particularmente de la resolución que ordenare o mantuviere la prisión preventiva (falso positivo), observada desde el tamiz de la declaración de error judicial.

Se previene desde ya que este no pretende ser un estudio holista de la institución del error judicial, así como tampoco de la prisión preventiva, sino que a partir de su comprensión e interrelación se busca desenmarañar la complejidad de la actividad probatoria en el ámbito cautelar penal.

El lenguaje empleado en estas páginas pretende huir de cualquier atisbo de erudición o encriptación, por lo que el problema a resolver se grafica mediante la siguiente pregunta guía: ¿Cómo podría la Corte Suprema calificar de error probatorio en los términos constitucionales, una resolución que ordenare o mantuviere la prisión preventiva, conforme la vulneración de un estándar cautelar penal indeterminado?

La base del problema es el paradigma de la prueba al que se adscriba. Propugnamos una mirada desde la denominada Teoría Racional de la Prueba, según se explicará. A partir de dicha teoría, se plantea como tesis principal que existe una incoherencia sistémica al pretender detectar un error probatorio en un régimen cautelar penal que carece de un estándar propio.

El estudio se divide en tres apartados: en primer lugar, fundamentaremos la questio facti del razonamiento probatorio, a partir de la comprensión e interrelación de las nociones de error y estándar; en segundo lugar, analizaremos los nudos críticos de la regla de suficiencia enunciada por el caso guía; y, en el tercer acápite, demostraremos que falta un estándar cautelar en donde afincar y dotar de contenido a la doctrina asentada por el máximo tribunal, conforme con un análisis normativo, dogmático y jurisprudencial.

\footnotetext{
${ }^{1}$ TwINING, 2006.
} 


\section{LA QUESTIO FACTI: ERROR Y ESTÁNDAR PROBATORIO}

\section{Fundamento ¿Por qué es necesaria una teoría racional de la prueba?}

En cualquier juicio, la función fundamental de la prueba es establecer la verdad de los hechos.

Conforme con la tradición racionalista, la actividad probatoria se compromete con el conocimiento, donde el proceso es un mecanismo teleológicamente ligado a la averiguación de la verdad y no a la resolución de controversias, ya que estas son inmanentes, incontrolables y no dependen de la racionalidad ${ }^{2}$.

Así, la prueba jurídica no difiere del resto del conocimiento humano: busca la verdad, reconoce el error, acoge la incertidumbre y se erige como una garantía para el ciudadano frente al adjudicador.

Sin perjuicio de lo anterior, desde un punto de vista normativo, no se propugna una importación de un modelo, conocido como Teoría Racional de la Prueba, sino que afincar el derecho a defensa en materia probatoria, por cuanto este presupone que las decisiones deben ser explicadas racionalmente y no a base de una mera convicción o creencia ${ }^{3}$, como si la decisión judicial fuera una epifanía. Cada decisión debe señalar expresamente los antecedentes en que se apoya, incluido el sustrato fáctico en una decisión cautelar ${ }^{4}$.

\section{El error y la actividad probatoria cautelar penal}

Resulta consustancial al ser humano la falibilidad de sus actos y por ello el sistema judicial debe reconocer la posibilidad latente de incurrir en yerros al dictar resoluciones judiciales y declarar probado un hecho en el proceso 5 .

${ }^{2}$ En doctrina, es posible distinguir dos escuelas procesales en abierta contraposición. Para los activistas, el proceso se aboca a la búsqueda de la verdad con un juez inquisidor; en cambio, para los garantistas el proceso apunta a la solución de conflictos, donde el juez es un garante de derechos. En este escenario, basta con establecer que, si bien entendemos que la verdad merece ser buscada, resulta evidente que el legislador chileno optó en materia cautelar penal por la tesis del proceso como garantía. Para un estudio acabado, Montero, 2006, pp. 130-165 y Peyrano, 2009.

${ }^{3}$ Ilustrativo es traer a colación las definiciones otorgadas por el Diccionario de la RAE, que explica que convicción es la "idea religiosa, ética o política a la que se está fuertemente adherido". Por su parte, creencia es el "completo crédito que se presta a un hecho o noticia como seguros o ciertos". Entendemos que, implícitamente, las definiciones dan cuenta de una aptitud proposicional subjetiva, pues la convicción emerge como incompatible con la duda, y la creencia, autónoma de la razón. Es por ello que, expresar las causas de una creencia (por ej., religión) bajo el supuesto de que se pueda, es algo muy distinto de motivar fácticamente una decisión.

${ }^{4}$ Artículo $19 \mathrm{~N}^{\circ} 3$ inciso $2^{\circ}$ CPR y a nivel convencional, artículo $14 \mathrm{~N}^{\circ} 3$ d) PIDCP y artículo $8 \mathrm{~N}^{\circ} 2$ b) $\mathrm{CADH}$. En doctrina, se explica que el fundamento de este derecho se encuentra en que sin el auxilio de un letrado, la defensa de los derechos puede resultar malograda, lo que no puede ser circunscrito a cuestiones de derecho. Cfr. Verdugo, Pfeffer y Nogueira, 1999, p. 219

${ }^{5}$ LaUdan, 2005, p. 97: distingue entre la condena de un inocente y la absolución de un culpable, denominándolos falso positivo y negativo, respectivamente. 
El reconocimiento del error como connatural al razonamiento judicial supone cuestionarse qué hacer frente a él. Nuestra respuesta: administrarlo, sin perjuicio de intentar aminorarlo; ¿cómo? mediante una regla de estándar o de suficiencia; ¿por qué?, proponemos que la justificación de su reconocimiento sea triple. En primer lugar, porque existe un cambio de paradigma en la forma de comprender la realidad, desde lo causal a lo probabilístico. Así, por difundido que sea, Newton yerra al sostener que la ley de causalidad regiría el universo, siendo esto un asunto de probabilidad ${ }^{6}$. En segundo término, porque en virtud de la forma del razonamiento judicial, esto es, la inferencia inductiva en donde la verdad de las premisas apoya la conclusión pero no la garantiza, este no puede alcanzar la certeza absoluta, como en las deducciones. De esta manera, la decisión se ha de medir en términos de verosimilitud ${ }^{7}$. Por último, debemos considerar el principio de inexcusabilidad que rige para el juez. Tanto el matemático como el médico no están obligados a resolver la ecuación ni a diagnosticar al paciente, respectivamente, si es que cuentan con información incompleta. Tampoco es posible exhortarles a decidir según su convicción o creencia ante la falta de evidencia. Por el contrario, el juez está compelido a resolver aun con insuficiente información o sin norma legal que lo rija ${ }^{8}$. Entonces, no sorprende que, incorporada la incertidumbre a la ecuación, un estándar de prueba no resulte ser una mera abstracción teórica sino una necesidad lógica, pues permite actuar considerando dicha incertidumbre que conducirá a errores más o menos aceptables.

Teniendo ello presente, revisaremos las particularidades del razonamiento cautelar penal.

En el ámbito del razonamiento cautelar en materia penal, si bien el proceso pugna con la incertidumbre, las decisiones judiciales se adoptan invariablemente sobre la base de información más o menos incompleta, sobre todo en el ámbito cautelar, en que el juez cuenta con poca información. Ello lo conduce a un razonamiento forzosamente prospectivo y con datos no elucidados, por lo que el legislador reconoce los principios de motivación y provisionalidad ${ }^{9}$.

De otro lado, cualquier medida cautelar penal y particularmente la prisión preventiva, reconoce como límite la presunción de inocencia ${ }^{10}$, que se erige como principio orientador del proceso penal y, específicamente, como regla de trato en materia cautelar. El Estado debe tratar al ciudadano como inocente hasta que un tribunal declare probada

\footnotetext{
${ }^{6}$ Explica el asunto GASCón, 2004, p. 21: "Los avances científicos posteriores, y en particular los de la física cuántica, al presentar una naturaleza gobernada por el principio de indeterminación, propician más bien la creencia contraria: el mundo físico (atómico) no está regido por leyes causales, sino probabilísticas”.

${ }^{7}$ En BAyón, 2008, p. 25.

${ }^{8}$ Consagrado en el artículo 76 inciso $2^{\circ}$ CPR y 10 del COT.

9 Artículo 122 CPP

${ }^{10}$ Pese a que la CPR no lo reconoce y se limita a proscribir la presunción de derecho de responsabilidad penal, su consagración normativa descansa en los artículos 11.1 de la DUDH, 14.2 del PIDCP, 8.2 de CADH y 4 del CPP.
} 
su culpabilidad conforme con un debido proceso ${ }^{11}$. Concordantemente, el legislador reconoce los principios de excepcionalidad e instrumentalidad ${ }^{12}$.

Finalmente, existe consenso en que la prisión preventiva se erige como la ultima ratio dentro de las medidas cautelares ${ }^{13}$. Solo puede ser decretada por un juez o tribunal penal, previa formalización, en audiencia pública y conforme con el principio de proporcionalidad.

\section{Marco dogmático de la acción por error judicial}

El principio de responsabilidad es un elemento integrante del Estado de Derecho y no constituye un "acto gracioso del Estado para con sus súbditos"14, conforme con los artículos 6 y 7 de la Carta Fundamental. En estas disposiciones se inserta la responsabilidad del Estado por "error judicial"15.

Su consagración normativa ${ }^{16}$ protege al ciudadano frente a la negligencia del Estado Juzgador. Las normas directamente estatuidas en el texto constitucional acotan la responsabilidad patrimonial del Estado Juzgador al ámbito penal, lo que desde el lenguaje de la epistemología jurídica se traduce en la sanción de falsos positivos.

No parece discutible colegir, en clave teórica, que toda persona tiene derecho a la reparación derivada de la privación a su libertad personal. Sin embargo, toda teorización se vuelve ingenua si se constata que su eficacia práctica ha sido marcadamente limitada a partir de una interpretación escasamente garantista ${ }^{17}$, cuestión que se explica por la interpretación restrictiva que se ha dado a la norma. Se ha enmarcado el actuar del juez, como sujeto activo imputable, en el delito de prevaricación y, con ello, se ha erigido un

${ }^{11}$ Artículo 150 inciso 3 CPP: "El imputado será tratado en todo momento como inocente".

${ }^{12}$ En nuestro medio, se propugna una tesis de compatibilidad entre la prisión preventiva y la aplicación de las medidas cautelares penales, basada en un juicio de razonabilidad y los principios de adecuación y proporcionalidad, en Nogueira 2005, p. 242 Coincidiendo, podemos señalar que lógicamente el inocente no se fuga ni reincide, por lo que la norma legal vulnera incluso lingüísticamente la presunción de inocencia.

13 Artículo 139 CPP y 9.3 PIDCP.

${ }^{14}$ GARrido, I999, p. 476.

${ }^{15}$ Por difundida que sea su denominación "responsabilidad por error judicial”, disentimos, ya que, en definitiva, se sanciona la negligencia y no todo error la configura.

${ }^{16}$ Artículo $19 \mathrm{~N}^{\circ} 7$ letra i) CPR "Una vez dictado sobreseimiento definitivo o sentencia absolutoria, el que hubiere sido sometido a proceso o condenado en cualquier instancia por resolución que la Corte Suprema declare injustificadamente errónea o arbitraria, tendrá derecho a ser indemnizado", y cuyo origen radica en la Carta Fundamental de 1925. Por su parte, a nivel convencional, encontramos los artículos 9.5 PIDCP y $10 \mathrm{CADH}$.

${ }^{17}$ En nuestro medio jurídico no abundan sentencias que acogen el error judicial. En total se han pronunciado siete sentencias que declaran su existencia en términos constitucionales conforme al metabuscador del Poder Judicial: Corte Suprema, causas roles No 27.762-1990, 802-1999, 5.411-2010, 25.568-2014, $1.579-2015,11.486-2017$ y 39.368-2017. 
estándar de imputación extremadamente difícil de superar ${ }^{18}$, resultando una cortapisa a su ejercicio en la práctica nacional ${ }^{19}$.

En nuestra opinión, para una correcta interpretación del instituto resulta esencial comprender que, desde un punto de vista formal, el objeto de la acción constitucional no es juzgar la conducta de los jueces (función represiva), sino permitir al inocente injustamente procesado o condenado el acceso a la justicia correctiva, excluyendo la "justa causa de error" a efectos de equilibrar los intereses en juego y de impedir la irresponsabilidad estatal pero sin constituir censura ni debilitamiento de la función jurisdiccional ${ }^{20}$.

\section{ANÁlisis CRÍtico DEL UMBRAL DE SUFICIENCIA EN EL CASO GUÍA}

\section{Justificación de la elección}

Seleccionamos la sentencia rol 1.579-2015 de la Excelentísima Corte Suprema porque es la única a la fecha que se pronuncia favorablemente respecto de la existencia en nuestro ordenamiento jurídico del error judicial en el ámbito cautelar penal. Ello no solo permite analizar críticamente los procesos valorativos e interpretativos contenidos en la resolución de instancia, sino que, además, los del máximo tribunal. Además, el caso guía permite revisar diversas aristas de interés probatorio que inciden en la hipótesis de la investigación, a saber: la sentencia consigna una regla de suficiencia cautelar que consiste en la seriedad, debiendo determinarse su función y contenido y, de manera secundaria, el rol pasivo que asume el tribunal en la aportación de antecedentes, aplicando el principio lógico de razón suficiente en la ponderación de los antecedentes tenidos a la vista. Finalmente, aplica el mismo estándar al arresto domiciliario.

${ }^{18}$ En tal sentido, CEA, 2008, p. 290: "el fallo o sentencia sean equivalentes al delito de prevaricación o torcida administración de justicia”. A su respecto, justifica dicho estándar BARros, 2007, pp. 524-525, para quien la morigeración de la culpa grave "importaría eventualmente un debilitamiento de la justicia, porque algún margen de error en la conducción de los procesos criminales es inevitable”. Al respecto, es ilustrativo reproducir ciertas disidencias dogmáticas, a saber, sería posible escindir el elemento subjetivo y rebajar la exigencia, pues "no puede haber arbitrariedades justificadas o parcialmente justificadas en un Estado de Derecho, y en consecuencia, no cabe duda que injustificadamente solo puede predicarse del error”, en PRECht, 2004, p. 177. Un paso más allá se puede ubicar la postura que lo funda en un factor de imputación objetiva atendiendo al principio pro homine, la ratio legis y la visión unitaria de la responsabilidad estatal. Así, Hernández, 1999, p. 471.

${ }^{19}$ Un análisis cuantitativo da cuenta de que durante igual periodo, años 2006 a 2018, conforme al meta buscador del Poder Judicial se ejercieron en total 63 acciones de declaración previa de error judicial, con tan solo 48 pronunciamientos de fondo, 15 inadmisibilidades por concepto de desistimiento (1), falta de copia (2), extemporaneidad (7) y ejercida contra resolución inimpugnable (5). En detalle, Corte Suprema, causas rol No 8.050-2012; 12.725-2011 y 4.965-2005; 2.180-2008, 5.612-2006, 8.320-2018, 92.7662016, 22.900-2015, 32.213-2014 у 9568-2014; 3.481-2006, 5.756-2005, 50.542-2018, 7.478-2013 y 19.263-2017, respectivamente.

20 ZúÑIGA, 2008, p. 39, propugna eliminar la calificación injustificadamente, pues "tal adverbio resulta contradictorio (en particular para la determinación de la arbitrariedad del juzgador) y basal para una lectura escasamente garantista como la hasta ahora imperante en la jurisprudencia”. 
Se reconoce que la sentencia, pese a su lenguaje anacrónico, homologa la prisión preventiva a la locución iusfundamental "someter a proceso", sin que haya sido necesaria una reforma constitucional ${ }^{21}$.

Finalmente, corresponde situar el pronunciamiento del máximo tribunal en su contexto: en nuestro país, solo entre 2006 y 2018, un total de 27.839 personas fueron sujetas a prisión preventiva o internación provisoria en causas que terminaron por absolución, sobreseimiento o ejercicio de la facultad de no perseverar ${ }^{22}$. Si bien el contraste es sugerente, nadie puede afirmar seriamente la existencia de 27.839 errores judiciales ¿Por qué? Esto se explica, a nuestro parecer, desde una faz probatoria debido a que el estándar de condena mediante una sentencia definitiva es manifiestamente superior al de sujeción a una medida provisional. A ello se añade que los antecedentes tenidos a la vista en una discusión cautelar y en el marco de una investigación en desarrollo pueden variar en el tiempo, por lo que una sentencia absolutoria precedida de una prisión preventiva no conlleva per se negligencia judicial.

\section{Aproximación al caso: bechos}

La Segunda Sala de la Corte Suprema acogió la solicitud de declaración previa de error judicial incoada por don Leonardo General y, por consiguiente, declaró que la resolución de 13 de julio de 2013 -que lo sometió a prisión preventiva como autor de tres delitos de violación-, y la resolución de 29 de octubre del mismo año -que le impuso la medida cautelar de arresto domiciliario nocturno-, dictadas en la causa RIT N ${ }^{\circ} 1.726-2013$ del Juzgado de Garantía de Los Andes, son injustificadamente erróneas o arbitrarias.

En su oportunidad, se formalizó al imputado por tres delitos de violación propia, perpetrados supuestamente contra la misma víctima -mayor de edad y conviviente de hecho de su sobrino- los días 26 de junio, 6 y 12 de julio de 2013. Coinciden las tres agresiones en el lugar de ocurrencia (domicilio de la víctima); la vía de acceso carnal (vaginal); en la intimidación (cuchillo o brazo); y en la justificación de ingreso del agresor al domicilio (realización de labores de construcción y reparación a su cargo). Difieren, en que la última agresión fue grabada por la víctima empleando un teléfono celular, acto seguido, develó y denunció.

El 13 de julio de 2013 el imputado fue formalizado y decretada a su respecto la medida de prisión preventiva, cautelar que se extendió por tres meses. Se fundó en la versión de la víctima, los dichos del testigo de oídas (conviviente y denunciante) y un video que da cuenta de una relación sexual entre víctima e imputado.

${ }^{21}$ Precht, 2004, p. 177: "deberá ser aplicada para ambos sistemas de justicia, en circunstancias que fue hecha teniendo en cuenta el procedimiento penal anterior”. Un antecedente jurisprudencial pretérito en Corte Suprema, 09.06.2014, rol 4.921-2014, considerando 5: "conforme a una interpretación axiológica, garantista y sistemática".

${ }^{22}$ Con mayor detalle, atendiendo al ámbito temporal de la medida cautelar: 7.195 personas estuvieron sujetas a prisión preventiva o internación provisoria por un periodo de 0 a 15 días; 15.400 personas por un periodo de 15 días a 6 meses; y 5.244 personas por un periodo superior a 6 meses, conforme a los informes estadísticos de la Defensoría Penal Pública, año 2006 a 2018. Véase: http://www.dpp.cl/repositorio/177/486. 
Finalmente, el Tribunal de Juicio Oral en lo Penal dictó unánimemente sentencia absolutoria basado en la nula credibilidad externa del relato de la víctima, estableciendo que el video de lo acaecido "fue fruto de la acción concertada y planificada de una aparente víctima y de su pareja, donde se aprecia que esta realiza todo este montaje para procurarse evidencia" 23 . Unido a eso, consideró las sendas contradicciones entre la víctima y el testigo de oídas y que el video se limita a establecer una relación sexual consentida, todo ello inserto en una "investigación desprolija que concluyó el mismo día que se inició" ${ }^{4}$. En consecuencia, el tribunal alzó todas las medidas cautelares (arraigo y arresto domiciliario).

\section{Análisis crítico propiamente tal}

Comprobar la hipótesis principal de esta investigación recaída en el estándar probatorio aplicable a la prisión preventiva, supone repensar íntegramente la actividad probatoria, integrada por tres momentos interrelacionados: la aportación de evidencia, la valoración, y la consecuente sujeción a una regla de estándar ${ }^{25}$.

\section{a) Razonamiento fundado en elementos subjetivos (“convicción”)}

Un estándar subjetivo no es estándar ${ }^{26}$, pues la convicción se aloja en el fuero interno del adjudicador ${ }^{27}$, puede subsistir contra la evidencia y no es graduable ni intersubjetivamente

23 TOP Los Andes, sentencia rit 26-2014, considerando 11.

${ }^{24}$ TOP Los Andes, sentencia rit 26-2014, considerando 11.

${ }^{25}$ La distinción es atribuible a Ferrer, 2007, p. 41. El crédito del jurista no exonera del deber de fundamentación normativa de su proposición en nuestro medio jurídico, pues el principio general de inclusión no está contenido explícitamente en alguna norma, aun cuando entendemos que integra la garantía constitucional del debido proceso, pues un proceso racional supone una decisión racional que, a su vez, requiere como insumo la incorporación de evidencia. Ello se manifiesta negativa y legalmente a propósito de las reglas de exclusión probatoria. Así, por ejemplo, en el artículo 318 del CPC ("hecho pertinente"), y en su par penal, el artículo 276 del CPP ("manifiestamente impertinentes”). Segundo, la valoración probatoria supone determinar la probabilidad de acaecimiento de un hecho conforme a la prueba. Coexisten diversos sistemas en nuestro medio: la sana critica en materia penal (artículo 297 CPP), familia (artículo 32 Ley $\mathrm{N}^{\circ}$ 19.968), laboral (artículo 456 del CT), Policía Local (artículo 14 Ley No 18.287); el sistema legal o tasado que pervive en materia civil, con la excepción de la discordancia en la prueba pericial por el artículo 422 CPC ("apreciará libremente") y artículo 428 del CPC ("más conforme con la verdad"). Inclusive, es posible encontrar manifestaciones del sistema de ponderación en conciencia en materia administrativa (artículo 35 Ley $\mathrm{N}^{\circ} 19.880$ ) y en la propia acción civil por error judicial (19 $\mathrm{N}^{\circ} 7$ letra i). Tercero, el estándar probatorio se erige como una regla de suficiencia a fin de adoptar una decisión que solo se instituyó formalmente a efectos de arribar a la condena penal, conforme lo dispuesto en el artículo 340 del CPP ("más allá de toda duda razonable").

${ }^{26}$ LAUDAN, 2005, p. 106: "Lo que observamos aquí no es un estándar de prueba sino una excusa o un pretexto débil para condenar o absolver".

${ }^{27}$ Estos, a su vez, no se pueden probar porque no pueden describirse como hechos, por lo que les resulta impropia la noción del error y no requieren de estándar de persuasión. 
controlable ${ }^{28}$. La sentencia guía no es del todo clara respecto de la forma en que entiende la prueba rendida, sea sobre la base de la convicción o de la razón.

En concreto, se lee en el fallo que "esta Corte ya ha señalado, para acceder a la declaración que trata el artículo $19 \mathrm{~N}^{\circ} 7$ letra i) de la Constitución Política de la República, que es necesario que se denuncien actuaciones de la judicatura desprovistas de elementos de convicción que habiliten su sustento racional o que fueron expedidas por voluntad meramente potestativa, caprichosa o insensata" 29 .

En esta parte, el razonamiento amerita, al menos, dos reparos.

Desde la tradición racionalista, la objeción consiste en el enlace forzado de la díada "convicción-razón", tal como si los elementos de convicción sirvieran de sustento a la calificación de una decisión como racional, cuando en realidad la racionalidad de una decisión está basada en sus fundamentos, precisamente, racionales.

Además, incluso desde la tradición subjetiva de la prueba, el argumento resulta inexacto pues son las razones las que permiten arribar a la convicción como aptitud proposicional de decisión, y no a la inversa.

Es por ello que la sentencia muestra, más que cualquier consideración teórica, que la carga de autoconvencimiento subsiste, al menos como germen, en nuestro medio y en el máximo Tribunal, respondiendo a una larga tradición dogmática-jurisprudencial de adoptar decisiones sobre la base de la convicción o creencia ${ }^{30}$.

En sana doctrina, es el juez quien debe explicitar su razonamiento y justificar su decisión acerca de los enunciados fácticos ${ }^{31}$, conforme con el principio de motivación que opera como una racionalización de la función jurisdiccional y que ha sido reconocida

${ }^{28}$ GONZÁLEZ, 2006, p. 112: explica que la concepción epistemológica subyacente es difícil de sostener, dado que le es indiferente la forma de razonamiento por la que se arribó a dicho convencimiento y no pareciera ser controlable racionalmente. Por contrapartida, Ferrer, 2003, p. 30: "decir que un hecho está probado es igual a decir que un determinado sujeto dotado de autoridad cree que ese hecho ha ocurrido. Siendo así, no queda ningún criterio intersubjetivo que permita decir que el sujeto en cuestión se equivocó”.

${ }^{29}$ Corte Suprema, 08.07.2015, rol 1.579-2015, considerando $7^{\circ}$.

${ }^{30}$ Concordamos con que el lastre de la noción subjetivista de la prueba ha resultado difícil de desterrar de nuestra tradición jurídica, pues persiste la asociación equívoca entre la libre valoración de la prueba y la creencia o convicción del juez como criterio de decisión. Cfr. Accatino, 2006, p. 18. En tal sentido, Gascón aclara que la libre convicción es una garantía epistémica y principio metodológico negativo, que consiste en el rechazo de la prueba legal como suficiente para determinar la decisión y no se constituye en un principio positivo de valoración libre o sin pruebas, en GASCón, 2004, p. 141-142. En otras palabras, concordamos en que no existe una exención al deber de motivación, pues valorar en conciencia debiera constituirse en un método "de persuasión racional y no de íntima convicción pues las cuidadosas exigencias establecidas en el derecho nacional sobre las formas de dictar sentencias conducen a esta conclusión”, en PEÑAILILLO, 1989, p. 91.

${ }^{31}$ Calamandrei, 1960, p. 118 postula que "entonces la motivación que es un balance escrito de la sentencia, de los fundamentos de hecho y de derecho que llevan al (por lo que podría calificarse de diario de viaje de la lógica judicial) constituye el trámite indispensable para introducir al lector dentro del pensamiento del juez, con el objeto de darle la posibilidad de controlar si en el camino de sus silogismos ha existido en cualquier punto, una caída o una desviación”. 
sistemáticamente por nuestra judicatura ${ }^{32}$. En este sentido, la doctrina que se lee en el considerando séptimo del caso guía no viene sino a reproducir una línea jurisprudencial decantada en el tiempo de confusión e interacción entre razonamiento y convicción ${ }^{33}$.

\section{b) Valoración probatoria cautelar penal: sana crítica}

La controversia giró en torno al enunciado "Es verdad que Leonardo General (imputado) ejerció fuerza o intimidación en la persona de X”.

En este punto, se ponderó como prueba débil el relato de la víctima, por cuanto "resulta claramente desprovisto de racionalidad y mínima sensatez (...) En efecto, la supuesta víctima no es una menor de edad, sino una persona de 30 años a la fecha del juicio, sin anomalías ni perturbaciones siquiátricas constatadas" ${ }^{44}$; y se razonó que no contribuye a la verdad del enunciado el testimonio de oídas que no dio noticia de conmoción o anormalidad en el comportamiento de la víctima, así como tampoco el video que se limita a constatar conductas comunes en un acto sexual consentido.

Cuando el tribunal subsume un enunciado fáctico en la hipótesis contenida en una norma general, ello implica un razonamiento inferencial y concreto basado en evidencia, antecedentes o indicios. Su objeto consiste en verificar el cumplimiento de los requisitos exigidos por la norma sin que dicha función quede condicionada a la etapa de juicio oral, sin perjuicio de reconocer escisiones terminológicas ${ }^{35}$ pues, en definitiva, aquí radica la legitimidad social de una decisión judicial. Sin fundamentación o motivación fáctica, el derecho es mera abstracción inaplicable ${ }^{36}$.

Además de las particularidades del razonamiento propias de una etapa preliminar, resulta manifiesto que la tarea encomendada al adjudicador -justificar fácticamente su decisión cautelar penal- supone la adhesión a un sistema de valoración, en la especie, sana crítica ${ }^{37}$. Arribamos a dicha conclusión por cuanto de la sentencia guía (conside-

${ }^{32}$ Lo que se ha venido expresando se manifiesta normativamente en la triada conformada por los artículos 36, 122 y 143 del CPP, que no son sino manifestación de la garantía constitucional de un "justo y racional procedimiento" contenida en el artículo $19 \mathrm{~N}^{\circ} 3$ inciso $6^{\circ}$ de la CPR. En tal sentido, ver la resolución dictada por la Corte Suprema, causa rol 13.185-2018, considerando $3^{\circ}$.

${ }^{33}$ Corte Suprema, 03.11.2009, rol 3.450-2008 y Corte Suprema, 11.05.2015, rol 25.658-2014.

${ }^{34}$ Corte Suprema, 8.7.2015, rol 1.579-2015, considerando $8^{\circ}$.

${ }^{35}$ En doctrina se distingue entre prueba y actos de investigación. Dada la centralidad del juicio oral y lo dispuesto en los artículos 140, 259 y 296 CPP, sostiene DECAP, 20 I 9, p 83: "que solo en la etapa de juicio es posible considerar el desahogo de pruebas” y GimenO, 20 I9, p 838: limita la prueba para la dictación de la sentencia en juicio oral. En esta línea, se ha resuelto que "el debate de modificación de medida cautelar, no es un debate de juicio, porque sencillamente en esta sede no se rinde la prueba que es la que asienta los hechos definitivos" en Corte Apelaciones Punta Arenas, 6.3.2020, rol 43-2020.

${ }^{36}$ Parece olvidar aquello el siguiente proyecto de ley: “Artículo único: a) Elimínense del artículo 140 del Código Procesal Penal, las expresiones 'que se cumplen los siguientes requisitos' y las letras a) y b), quedando, como único requisito la contemplada en la letra c), de este artículo”, en Boletín No 8046-07. La valoración probatoria constituye una condición mínima de racionalidad del ejercicio del poder estatal.

${ }^{37}$ Isensse, 2018, p. 150: por así disponerlo el artículo 297 del Código Procesal Penal, sin excepción. 
randos octavo y noveno) se desprende que el máximo tribunal aplicó: reglas de la lógica o razón suficiente, al constatar que ni el video ni el relato del testigo de oídas contribuyen a acreditar la fuerza o intimidación; conocimientos científicamente afianzados, al reprochar la ausencia de peritaje médico de lesiones; y máximas de la experiencia, al señalar que una mujer de 30 años y con hijos, sabe cómo reaccionar frente a un intento de violación, aspecto que mermó la credibilidad del relato de cargo.

Finalmente, resta por caracterizar la valoración probatoria como un análisis prospectivo, concreto y fundado en información limitada en el marco de una investigación en desarrollo, elementos que han de ser aportados por los intervinientes ${ }^{38}$.

c) Sujeción a una regla de estándar ¿inconsistencia sistémica?

Al respecto, es ilustrativo reproducir parte de la sentencia de la CS: "De esa forma respecto de ninguno de ellos se contaba con elementos serios que avalaran las conclusiones del tribunal en orden a tener por 'acreditado' como lo indicó en su resolución el delito materia de la formalización. Esto se ve ratificado por el propio tenor de la resolución de la jueza de garantía, la que nada dice o precisa para justificar"39.

Pareciera, entonces, que nuestra hipótesis inicial ha sido refutada en la medida que la sentencia dictada por la Corte Suprema dio por no superado el parámetro de suficiencia después de valorar la prueba, es decir, la seriedad tanto de la prisión preventiva como del arresto domiciliario.

Empero, según observaciones anteriores, determinar si la seriedad -o cualquier otra expresión- constituye un verdadero estándar probatorio no solo supondrá constatar su consagración formal sino, necesariamente, determinar su contenido y ámbito de aplicación.

Previamente conviene resolver la cuestión acerca de por qué sería necesario un estándar de prueba en el caso de marras. En nuestra opinión, por la concurrencia de dos factores: en abstracto, debido a que estos umbrales cumplen una función heurística de la valoración y justificadora de la decisión ${ }^{40}$, erigiéndose en una garantía para el ciudadano en una realidad tamizada por la probabilidad draconiana. Sin la definición cualitativa, moral y no epistemológica del grado de fundamentación fáctica requerido para dar por acreditada una hipótesis de hecho fundante de prisión preventiva, el máximo tribunal

\footnotetext{
38 Concordamos con el rol "pasivo" que le atribuye el máximo tribunal al adjudicador en dicha tarea, conforme al paradigma adversarial. En este sentido, la Corte Suprema, causa rol 4.921-2014, considerando 10, señala que: "en un sistema procesal informado por los principios de contradicción, bilateralidad de la audiencia, y de imparcialidad del tribunal, la proactividad que echa de menos el peticionario, la ley la espera hoy del defensor”. Ídem, Corte Suprema, 28.11.2017, rol 33.813-2017, considerando $9^{\circ}$.

${ }^{39}$ Corte Suprema, 8.7.2015, rol 1.579-2015, considerando 9.

${ }^{40}$ En doctrina, PARdo, 2013, pp. 102-103: le atribuye fines de corrección y distribución de riesgo. Por su parte, Coloma, 2009, p. 211 propugna que: contribuyen a "definir cuánta información y análisis será requerido para superar las exigencias inherentes a la carga de la prueba que ha sido impuesta sobre una de las partes". Finalmente, Nieva, 2010, p. 90 sostiene que: "no son sino frases o expresiones elegantes, que pretenden ser muy esclarecedoras para un lego [jurado] de cuál es su misión”.
} 
estaría lógicamente impedido de declarar un error judicial probatorio consecuente, pues no podría lógicamente dar por no superado un listón o estándar, si aquel permanece indeterminado o no especificado en el artículo 140 del CPP.

Ahora bien, cabe preguntarse por qué sería necesario fundar la seriedad invocada. La respuesta es que sin fundamentación, la seriedad queda vaciada de contenido, meramente adjetiva, erigiéndose en una fórmula que en sí misma no puede justificar cuándo la prueba dispone de dicha calidad y cuándo no. Vale decir, no servirá para justificar la decisión. En este sentido, en cuanto a la atribución de contenido, el máximo tribunal no explicita el sentido y alcance de la invocada seriedad (ni en el considerando décimo ni en el resto del fallo), limitándose a calificar la prueba. Olvida que esta es la ratio decidendi de la acción invocada en el caso concreto, perdiendo la oportunidad de afianzar su doctrina, cuestión que resultaba esencial considerando que se aboga por un criterio o estándar, sin consagración a nivel normativo, a saber, la "seriedad".

Esta crítica debe ser, sin embargo, matizada pues el fallo restó valor a prácticamente todos los elementos de aportación probatoria recaídos en la existencia de la violencia o intimidación, razón por la que el asunto no ameritaba mayores razonamientos abstractos para su resolución.

Finalmente, cabe preguntarse acerca del ámbito de aplicación de la invocada seriedad como parámetro probatorio. La sentencia guía la aplica al arresto domiciliario ${ }^{41}$, pero claramente este importa un grado de afectación a la libertad personal menor que la prisión preventiva. Según la distribución de errores de las medidas cautelares personales ${ }^{42}$, resulta que solo constituye un acertado fundamento para la prisión preventiva.

En definitiva, aun reconociéndole mérito al fallo, queda abierta la pregunta por el estándar de prueba aplicable en el sistema cautelar penal.

${ }^{41}$ Corte Suprema, 8.7.2015, rol 1.579-2015, considerando $10^{\circ}$ : "así como la de 29 de octubre de 2014 que le impuso la medida cautelar de arresto nocturno domiciliario la que no hace más que reiterar los errores de la primera y que, por ende, no amerita su análisis particular".

42 Tal como se indicó, la distinción descansa en la administración del riesgo de equivocación, razón por la que las medidas cautelares contenidas en el Párrafo $6^{\circ}$ del Libro I se rigen por los controles y requisitos aplicables a la prisión preventiva solo en cuanto no fueren incompatible. En consecuencia, la remisión no es absoluta sino que atiende a la naturaleza de las medidas que se pretenden decretar, caracterizadas por una distinta afectación a la libertad ambulatoria. Concuerda, DUCE y RIEGO, 2007, p. 281: para quienes todas afectan la prisión preventiva y "requieren un fundamento fuerte, no obstante, la intensidad de la afectación evidentemente condiciona su propio fundamento. Por lo tanto, es probable que en el caso de medidas de muy baja intensidad, el juez se conforme con un caso menos fuerte". 


\section{HACIA LA BÚSQUEDA DE UNA REGLA DE SUFICIENCIA EN EL ORDENAMIENTO JURÍDICO}

\section{Primera aproximación: análisis normativo}

Para efectos de ordenar la prisión preventiva se exige "a) Que existen antecedentes que justificaren la existencia del delito que se investigare; b) Que existen antecedentes que permitieren presumir fundadamente que el imputado ha tenido participación en el delito como autor, cómplice o encubridor, y c) Que existen antecedentes calificados que permitieren al tribunal considerar que la prisión preventiva es indispensable para..." ${ }^{43}$.

a. En cuanto al primer requisito (art. 140 letra a), se trata del presupuesto material o Fumus comissi delicti. En particular, la existencia del delito.

Se exige por el legislador que medien antecedentes y que estos sean justificados. "Antecedente" es todo dato que da cuenta de una circunstancia de hecho en que se basa una decisión. Por su parte, basta con entender que justificar es "probar algo con razones convincentes" 44 .

El legislador exige la justificación, connatural a toda resolución, pero no se hace cargo de la distribución de los errores, y particularmente, de cuándo la decisión estará probatoriamente justificada.

b. En cuanto al presupuesto material o Fumus comissi delicti, en particular, la participación (art. 140 letra b)

Se exige por el legislador que medie una presunción y que esta sea fundada, exigencia que está lejos de constituir un estándar probatorio.

Sintéticamente, una presunción es un instrumento cognoscitivo distinto de la prueba. Constituye un mecanismo inferencial que permite enfrentar la incertidumbre y cuyo nexo desde lo conocido hacia lo desconocido o presumido, es una máxima de la experiencia ${ }^{45}$. Por su parte, el calificativo "fundada" resulta un reforzamiento de la intención del legislador de descartar las meras sospechas o suposiciones.

La norma consagró una presunción simple o judicial que instruye al juez cómo inferir y no cuándo dar por acreditado un hecho. Es decir, su influjo radica en paralelo a la valoración, y ciertamente, no entorno a la determinación de un estándar de prueba ${ }^{46}$.

\footnotetext{
43 Artículo 140 CPP.

${ }^{44}$ Diccionario Real Academia Lengua Española.

${ }^{45}$ Se definen como "razonamientos del legislador o del juez en los que se parte de un hecho conocido para determinar la existencia de un hecho ignorado”, en GAMA, 2013, p. 69.

${ }^{46}$ Lo explicado dice relación únicamente con la presunción judicial y no con las presunciones legales absolutas (de derecho) o relativas (simplemente legales), por cuanto "ella se basa en reglas de experiencia humana y opera en el momento de la valoración de la prueba, a diferencia de una presunción legal, que no
} 
Cabe destacar que el razonamiento presuntivo no enerva la necesidad de un estándar probatorio tendiente a acreditar la participación del imputado, por dos razones. Primero, porque este presupone la prueba del hecho conocido que sirve de base para inferir el hecho desconocido, lo que conlleva necesariamente un umbral para dar por establecido aquél; y segundo, porque las máximas de la experiencia, en cuanto juicios lógicos fundados en regularidades empíricas, deben ser acreditadas, sin perjuicio de reconocer excepcionales juicios hipotéticos de contenido general que no admiten cuestionamiento, tal como, que el sol sale todas las mañanas por el Este y se pone por el Oeste. De este modo, resulta que el juez, al emplear una máxima de la experiencia como núcleo de una presunción judicial, razona por regla general en forma inductiva $y$, en consecuencia, su inferencia en la casi totalidad de casos es probabilística, por lo que requiere un umbral de certeza fáctica $^{47}$. Nótese que esta cuestión no es una mera abstracción teórica, sino que es una exigencia de racionalidad que se introduce en nuestro medio jurídico vía requisito de gravedad, connatural a toda presunción judicial ${ }^{48}$.

c. En cuanto al presupuesto "necesidad de cautela" o periculum libertatis (art. 140 letra c)

Tradicionalmente, esta exigencia no despierta mayor debate probatorio. Siendo un asunto de argumentación jurídica, se satisface aplicando el principio de proporcionalidad.

Pese a ello y partir de la interrelación entre el hecho y el derecho, es de interés asentar probatoriamente que:

- En el encabezado, el legislador mandata constatar la existencia de evidencia ("antecedentes") y de dotarla de una cualidad ("calificar"), todo con un carácter instrumental ("indispensable para”);

- El inciso $2^{\circ}$ regula la obstaculización de la investigación, exigiendo la acreditación de sospecha grave y fundada para su procedencia. La ley no señala circunstancias o factores, sino más bien enumera ejemplos;

necesariamente refleja una máxima de la experiencia y cuyo momento en el proceso es el de la carga de la prueba”. Larroucau, 2015, p. 28.

47 Para un argumento completo, véase GAMA, 2013. p. 85.

${ }^{48}$ Explica el requisito de gravedad Taruffo, para quien responde a la "naturaleza probabilística que es propia, en la casi totalidad de los casos, de las inferencias presuntivas. Así pues, si se quiere ir más allá de las definiciones genéricas y meramente alusivas para utilizar nociones en alguna medida más rigurosas, debe hacerse referencia al concepto de probabilidad prevaleciente”. TARUFFo, 2005, p. 475. En tal sentido, normativamente hay que tener a la vista los artículos 1712 CC, 426 CPC y 52 CPP. 
- Los incisos $3^{\circ}$ y $4^{\circ}$ abordan la afectación a la seguridad de la sociedad ${ }^{49}$, elemento vago y no definido, aunque se fijen elementos indiciarios;

- $\quad$ El inciso $5^{\circ}$ propugna un racionamiento presuntivo simple.

\section{Segunda aproximación: análisis dogmático}

En algunas materias el legislador definió el estándar de prueba aplicable y en otras no. En estas últimas, corresponde a la doctrina y a la jurisprudencia, como partes integrantes del sistema jurídico, suplir el silencio legal.

A continuación, se sistematiza la doctrina que se ha pronunciado a este respecto.

\section{a) Postura que no reconoce un estándar}

Según Caroca "el CPP al transcribir las normas del antiguo Código usa una terminología inadecuada, ya que exige que 'existan antecedentes que permitan presumir fundadamente' que el imputado ha tenido participación en el 'delito', lo cierto es que la libre valoración de la prueba descarta la existencia de tales presunciones y menos del delito, que en esos momentos aún no se puede decir si se ha cometido" 50 .

Disentimos de la opinión planteada. En primer lugar, porque el sentido de la voz "delito" es una locución que atiende a requisitos sustantivos. Por consiguiente, su exigencia puede estar sujeta a diversos estándares probatorios conforme al riesgo que se administra. Por el contrario, la crítica esbozada por el autor supone una falta de reconocimiento de la divergencia, ergo, del razonamiento probatorio. Y en segundo, porque el razonamiento presuntivo que se propugna es judicial y no legal, por lo que resulta compatible con el razonamiento probatorio, con el que incluso se emparenta ${ }^{51}$.

Como se comprenderá, no es que el autor sea explícito en negar el estándar, pero su forma de razonamiento da cuenta mínimamente de su reconocimiento.

b) Postura de la necesidad de un estándar, pero con determinación vaga

Horvitz y López explican que el juez, al momento de apreciar los elementos de prueba, puede estar ante la duda, la probabilidad o la certeza; para luego dar cuenta de

${ }^{49}$ La legitimidad política criminal del instituto ha sido objeto de arduo debate y álgido cuestionamiento desde la faz del Derecho Internacional de los Derechos Humanos, erigiéndose, para sus críticos, la causal en una anticipación punitiva. Sobre el asunto Dei Vecchi, 2013, pp. 189-217; y Horvitz y López, 2008, p. 389.

${ }^{50}$ Caroca, 2005, p. 191.

${ }^{51}$ Larroucau, 2015, p. 27: vincula sana crítica, presunción judicial y decisión judicial al explicar que "una presunción judicial, lo mismo que la sana critica, articula una forma de razonamiento para inferir un hecho desconocido a partir de uno conocido. En otros términos, tanto el esquema de esta presunción - gravedad, precisión y concordancia- como el de la sana critica-ciencia, lógica y experiencia- instruyen a un juez acerca de cómo inferir, no que inferir". 
que se acepta generalmente que el estándar requerido para la prisión preventiva consiste en un mero juicio de probabilidad ${ }^{52}$.

Desde una faz valórica, Isensse postula que deberá ser superior al civil pero inferior al de la sentencia definitiva penal ${ }^{53}$. En igual sentido Aedo ${ }^{54}$.

Por su parte, Riego avanza al exigir una prognosis de "una sólida expectativa de que los cargos serán llevados a juicio" 55 .

Finalmente, Cerda precisa que "debe tratarse de elementos de información objetivos, serios y convincentes" 56 .

\section{c) Postura que reconoce la necesidad de un estándar y propugna uno}

Descriptivamente, Beltrán promueve un estándar sui generis, según el que no bastaría con "tener por probada sin más la hipótesis que tenga un grado de confirmación mayor, sino, adicionalmente, exigir que además de tener un grado de confirmación mayor, se alcance un quantum de confirmación determinado" 57 .

Analíticamente, en tanto, Valenzuela sostiene que la evidencia disponible debe ser sometida a "1) la hipótesis de hecho debe ser capaz de explicar los datos disponibles, integrándolos de forma coherente; 2) Las predicciones de nuevos datos y sus correlativas hipótesis de hecho deben haber resultado confirmadas; 3) Deben formularse predicciones basadas en las evidencias que permitan que se acepte como probable un determinado enunciado sobre hechos" 58 .

Dado este escenario, propugnamos que:

i. A toda medida cautelar penal se le ha de exigir acreditación conforme al estándar de grado mínimo necesario de probabilidad prevaleciente;

ii. Conforme a la regla anterior, debe atenderse al riesgo que se administra: mayor o menor afectación a la libertad ambulatoria del imputado. En el caso de la prisión preventiva, el juez debe exigir una mayor acreditación; y que,

52 Horvitz y López, 2008, p. 401. De la simple lectura se les reconoce el mérito de afincar el razonamiento probatorio en un ámbito probabilístico, pero no dan luces de su quantum.

53 ISENSSE, 2018, p. 154.

${ }^{54}$ AEdo, 2017, p. 43: "el uso de un estándar muy elevado es imposible de alcanzar en los inicios del proceso penal y, por otro lado, la exigencia de un estándar inferior es inaceptable en un sistema protector de derechos fundamentales".

55 Riego, 2013, p. 247. Estimamos de mayor contenido que la mera exigencia de probabilidad, la locución "sólida expectativa", pues, exegéticamente, una expectativa supone la probabilidad razonable de que algo suceda.

56 CERDA, 2005, p. 141

57 Beltrán, 2012, pp. 472-473. Una opinión crítica a la propuesta sostiene Hadwa, para quien esta tesis difícilmente podría ser aceptada, ya que tanto el estándar de la duda razonable, como el de la preponderancia de la evidencia, se encuentran conectados a realidades procesales definitivas y en donde ya se aplicaron reglas contra epistémicas. HADWA, 2015, p. 107.

58 ValenZuela, 2017, pp. 81-82. 
iii. La presunción de inocencia es una garantía vertebral del proceso penal compatible con la aplicación de medidas cautelares personales ${ }^{59}$, limitándose su función como regla de trato. En consecuencia, la eventual plausibilidad de la tesis de defensa no merma la fuerza probatoria de la tesis de cargo ${ }^{60}$.

\section{Tercera aproximación: análisis jurisprudencial}

Finalmente, como la doctrina no es fuente formal del derecho, sistematizamos a continuación jurisprudencia relevante.

A nivel convencional, la Corte Interamericana de Derechos Humanos estableció, aunque sin definir, dos exigencias en torno al umbral de suficiencia cautelar-penal: la probabilidad ("grado") y la razonabilidad ${ }^{61}$.

En concreto, exige que "la sospecha tiene que estar fundada en hechos específicos, esto es, no en meras conjeturas o intuiciones abstractas" 62 .

A nivel nacional, en tanto, cabe prevenir que la oralidad y la protocolización limitan el acceso a fallos de interés, empero, son doctrinas decantadas por el máximo tribunal las siguientes:

a) La menor exigencia probatoria de la decisión cautelar respecto del umbral de condena

Así, se ha resuelto que "el mero hecho de un laudo absolutorio no transforma automáticamente al auto de procesamiento en injustificadamente erróneo o arbitrario, por cuanto son dos momentos procesales diferentes que requieren de grados de convicción distintos" 63 .

En el mismo sentido, se ha dicho que "una decisión condenatoria demanda un estándar más elevado de convicción que aquel requerido para decretar la prisión preventiva"64.

${ }^{59}$ Ferrer, 2010, p. 11: "el debate entre abolicionistas (de la prisión preventiva o de la presunción de inocencia) y compatibilistas sería, más bien, un debate acerca de los límites de la presunción de inocencia como regla de trato procesal".

${ }^{60}$ Valenzuela, 2018, p. 851: "Este es un caso donde esa regla no recibe aplicación y el juez puede entender que hay suficiencia de la evidencia de la medida cautelar aún en casos en que pervivan hipótesis de hecho compatibles con la inocencia del acusado". Esto, no obsta a nuestro entender, a la necesidad de hacerse cargo de las alegaciones de la defensa respecto de la tesis de imputación fiscal. En tal sentido, Corte Apelaciones Concepción, 13-12-2019, rol 254-2019, considerando 7 y Corte Suprema, 19.10.2017, rol 40860-2017, considerando 6.

${ }^{61}$ Corte Interamericana de Derechos Humanos, Palamara Vs. Chile, considerando 206.

${ }^{62}$ Corte Interamericana de Derechos Humanos, Norín Vs. Chile, considerando 311.

${ }^{63}$ Corte Suprema, 24.05.2011, rol 2.804-2010, considerando 14.

${ }^{64}$ Corte Suprema, 20.04.2015, rol 22.356-2014, considerando 11. Idéntica doctrina en Corte Suprema, 6.6.2018, rol 44.656-2017, considerando 10 . 
b) En el camino hacia un umbral de verosimilitud

Se suele exigir que "deben existir antecedentes de cargo que deben ser dilucidados en un juicio de probabilidad y que efectuado el mismo por esta Corte, permiten en esta etapa atribuir a los imputados razonablemente los hechos" 65 .

Asimismo, a la "misma conclusión llega el tribunal a quo, cuando señala que solo hay indicios, y que estas no constituyen necesariamente presunciones fundadas de participación" 66 y "No se trata de determinar en esta instancia procesal, la culpabilidad o inocencia de los imputados, sino sólo si su libertad representa o resulta peligrosa para la seguridad de la sociedad o constituye un obstáculo insalvable para el éxito de la investigación" 67 .

Según lo expuesto, en la jurisprudencia coexisten resoluciones erróneas en que se ha denegado la prisión preventiva "al no existir en esta etapa, certeza respecto de la concurrencia del verbo rector del tipo penal" 68 , o simplemente, se ha concedido frente a la mera enunciación o constatación de antecedentes ${ }^{69}$.

\section{Conclusiones}

1. El error es incompatible con la convicción, pues esta, como aptitud proposicional, no se compromete con la verdad desde que justificar un estado interno o del alma es muy distinto a motivar fácticamente una decisión.

2. En nuestro medio jurídico y según el análisis normativo, doctrinal y jurisprudencial, no existe un estándar cautelar penal decantado a efectos de conceder la medida cautelar de prisión preventiva, sin perjuicio de reconocerse mérito de la sentencia guía en tal sentido.

3. Previo a una valoración acuciosa de la prueba, la sentencia guía tiene el mérito de erigir la "seriedad" (considerando $10^{\circ}$ ) como un estándar cautelar penal, expresión nada antojadiza, pues también es empleada por la doctrina especializada.

Por el contrario, se puede constatar que la carga de autoconvencimiento subsiste al menos como germen conceptual en el considerando $7^{\circ}$ de la sentencia, lugar en que el tribunal emplea en una misma frase elementos subjetivos ("convicción") y objetivos ("razón") en una abierta relación asistémica.

\footnotetext{
${ }^{65}$ Corte Apelaciones Punta Arenas, 23.8.2018, rol 158-2018, considerando 4.

${ }^{66}$ Corte Apelaciones Santiago, 6.1.2020, rol 63-2020, considerando 2.

${ }^{67}$ Corte Apelaciones Temuco, 27.7.2018, rol 618-2018, considerando 1.

${ }^{68}$ Corte Apelaciones San Miguel, 6.1.2020, rol 21-2020, considerando 2.

${ }^{69}$ Corte Apelaciones Coyhaique, 8.11.2019, rol 8-2017. Es por ello, que se deniega la declaración de error judicial frente a la mera constatación de antecedentes de convicción y sin ponderar en Corte Suprema, 25.02.2019, rol 12.852-2018, considerando 7 y Corte Suprema, 9.05.2017, rol 70.829-2016, considerando 4.
} 
4. Siendo una decisión valorable desde el punto de vista político, a fin de contribuir a la discusión, propugnamos que el estándar cautelar penal debe situarse entre la exigencia mínima de la probabilidad prevaleciente y necesariamente bajo el umbral de condena, conforme a la menor o mayor afectación de la libertad ambulatoria de la medida cautelar personal decretada.

\section{BIBLIOGRAFÍA}

Accatino, Daniela, 2006: "La fundamentación de la declaración de hechos probados en el nuevo proceso penal. Un diagnóstico", Revista Derecho (Valdivia), Vol. 19, N² 2

AEdo, Francisco, 2017: Estándares de convicción para el otorgamiento de medidas cautelares personales en el proceso penal, Valparaíso.

Barrros, Enrique, 2007: Tratado de responsabilidad extracontractual, Santiago: Jurídica de Chile.

BAYón, Juan Carlos, 2008: "Epistemología, moral y prueba de los hechos: hacia un enfoque no benthamiano", Analisi e diritto, No 2008.

Beltrán, Ramón, 2012: "Estándares de prueba y su aplicación sobre el elemento material de la prisión preventiva en Chile", Política Criminal, Vol. 7, N 14.

Calamandrei, Piero, 1960: Proceso y democracia, Héctor Fix (trad.), Buenos Aires: Jurídica Europa - América.

Caroca, Alex, 2005: El nuevo sistema procesal penal ( $3^{a}$ edición), Santiago: Lexis Nexis.

Cea Egaña, José, 2008: Derecho Constitucional Chileno, Santiago: Universidad Católica.

CERDA, Rodrigo, 2005: Manual del nuevo sistema de justicia criminal (1 ${ }^{a}$ edición), Santiago: Librotecnia.

Coloma, Rodrigo, 2005: "Estándares de prueba y juicios por violaciones a los Derechos Humanos", Revista Derecho (Valdivia), Vol. 22, N².

DeCAP, Mauricio, 2019: La prueba en materia sustantiva civil, Santiago: Jurídica de Chile.

Dei Vecchi, Diego, 2013: "Acerca de la justificación de la prisión preventiva y algunas críticas frecuentes”, Revista Derecho (Valdivia), Vol. 26, No 2.

Duce, Mauricio y Riego, Cristián, 2007: Proceso Penal, Santiago: Jurídica de Chile.

FERrER, Jordi, 2003: "Derecho a la prueba y racionalidad de las decisiones judiciales", Jueces para la democracia, No 47.

Ferrer, Jordi, 2007: La valoración racional de la prueba, Madrid: Marcial Pons.

FERRER, Jordi, 2010: "Una concepción minimalista y garantista de la presunción de inocencia", Revista Maestría en Derecho Procesal, Vol. 4, No 1.

Gama, Raymundo, 2013: "Concepciones y tipologías de las presunciones en el derecho continental”, Revista Estudios de la Justicia, N ${ }^{\circ} 19$.

Garrido, Mario, 1999: "La indemnización por error judicial en Chile”, Revista Ius et Praxis, Volumen 5, $\mathrm{N}^{\circ} 1$.

Gascón, Marina, 2004: Los hechos en el derecho. Bases argumentales de la prueba, Barcelona: Marcial Pons.

Gimeno, Vicente, 2019: Derecho Procesal Penal, Madrid: Editorial Civitas.

GonzÁlez, Daniel, 2006: “Argumentación y prueba judicial” en Carbonell, Orozco y Vázquez (coord.), Estudios sobre la prueba, México: Universidad Autónoma.

Hadwa, Marcelo, 2015: La prisión preventiva y otras medidas cautelares personales (2a edición), Santiago: Jurídica de Chile.

Hernández, Domingo, 1999: “Error judicial: ensayo de interpretación constitucional”, Revista Ius et Praxis, Vol. 5, $\mathrm{N}^{\circ} 1$. 
Honvitz, María Inés y López, Julián, 2008: Derecho Procesal Penal Chileno, T.I, Santiago: Jurídica de Chile.

Isensse, Carlos, 2019: Prueba y medidas cautelares en el derecho administrativo sancionador, penal y civil, Santiago: Librotecnia.

Larroucau, Jorge, 2015: "Sana crítica y presunción judicial", Revista Derecho Universidad de Concepción, $\mathrm{N}^{\circ} 238$.

LaUdan, Larry, 2005: "Por qué un estándar de prueba subjetivo y ambiguo no es un estándar", Doxa, Cuadernos de filosofía del derecho, $\mathrm{N}^{\circ} 28$.

Nieva, Jordi, 2010: La valoración de la prueba, Madrid: Marcial Pons.

Nogueira, Humberto, 2005: "Consideraciones sobre el derecho fundamental a la presunción de inocencia”, Revista Ius et Praxis, Vol. 11, No 1.

PARdo, Michel, 2013: "Estándares de prueba y teoría de la prueba”, en Carmen Vázquez (ed.), Estándares de prueba y prueba científica. Ensayos de epistemología jurídica, Madrid: Marcial Pons.

PeÑallillo, Daniel, 1989: La prueba en materia sustantiva civil, Santiago: Jurídica de Chile.

PRETCH, Jorge, 2004: "Resolución injustificadamente errónea o arbitraria en la indemnización por error judicial”, Estudios constitucionales, Vol. 2, No 1 .

Riego, Cristian, 2013: "La audiencia para debatir la prisión preventiva y sus distintos componentes”, en Duce, Podestá, Riego y Villadiego, Prisión Preventiva en América Latina. Enfoques para profundizar el debate, Santiago: Centro Estudio de Justicia de las Américas.

TARuffo, Michele, 2005: La prueba de los hechos, España: Trota.

Twining, William, 2006: "De nuevo, los hechos en serio", Doxa, Cuadernos de Filosofía del Derecho, No 32 .

VAlenZuela, Jonatán, 2018: "Hacia un estándar de prueba cautelar en materia penal: algunos apuntes para el caso de la prisión preventiva”, Revista Política Criminal, Vol. 13, No 26.

Valenzuela, Jonatán, 2017: Hechos, pena y proceso, Santiago: Rubicón Editores.

Verdugo, Mario, Pfeffer, Emilio y Nogueira, Humberto, 1999: Derecho constitucional, T.I, Santiago: Jurídica de Chile.

Vivanco, Ángela, 2015: Curso de Derecho Constitucional (3a edición), T.I, Santiago: Universidad Católica de Chile.

ZÚÑIGA, Francisco, 2008: "La acción de indemnización por error judicial”, Estudios constitucionales, $\mathrm{N}^{\circ} 2$.

\section{Normas jurídicas citadas}

Ley No 1.552, Código de Procedimiento Civil, publicada con fecha 30 de agosto de 1902.

LEy N $\mathrm{N}^{\circ}$ 7.421, Código Orgánico de Tribunales, publicada con fecha 9 julio de 1943.

LEY N $N^{\circ}$ 18.287, Establece procedimiento ante los Juzgados de Policía Local, publicada con fecha 7 de febrero de 1984.

Pacto Internacional de Derechos civiles y Políticos, adoptado con fecha 30 noviembre de 1976. Publicado en Chile con fecha 29 de abril de 1989.

Convención Americana sobre Derechos Humanos, adoptada con fecha 23 agosto de 1990. Publicado en Chile con fecha 5 enero de 1991.

Ley No 19.696, Código Procesal Penal, publicada con fecha 12 octubre de 2000.

D.F.L.No 1 , Código del Trabajo, publicada con fecha 16 enero de 2003.

LEY N 19.880 , Establece bases de los procedimientos administrativos que rigen los actos de los órganos de la administración del Estado, publicada con fecha 29 mayo de 2003.

Ley N $N^{\circ}$ 19.968, Crea los Tribunales de Familia, publicada con fecha 30 agosto de 2004. 
Decreto No 100, Constitución Política de la República, publicada con fecha 22 septiembre de 2005 .

Proyecto de ley que adecua los artículos 140 y 141, ambos del Código Procesal Penal a la Constitución Política de la República, en materia de prisión preventiva, Boletín No 8046-07.

\section{Jurisprudencia citada}

Corte Suprema, sentencia de fecha 17 noviembre de 1999, rol 802-1999.

Corte Suprema, sentencia de fecha 5 diciembre de 1990, rol 27.762-1990.

Corte Interamericana de Derechos Humanos, sentencia de fecha 22 noviembre de 2005, Palamara Vs. Chile.

Corte Suprema, sentencia de fecha 24 mayo de 2011, rol 2.804-2010.

Corte Suprema, sentencia de fecha 11 agosto de 2011, rol 5.411-2010.

Corte Interamericana de Derechos Humanos, sentencia de fecha 29 mayo de 2014, Norín Vs. Chile.

Corte Suprema, sentencia de fecha 9 junio de 2014, rol 4.921-2014.

Tribunal Oral en lo Penal Los Andes, sentencia de fecha 30 agosto de 2014, rit 26-2014.

Corte Suprema, sentencia de fecha 20 abril de 2015, rol 22.356-2014.

Corte Suprema, sentencia de fecha 11 mayo de 2015, rol 25.568-2014.

Corte Suprema, sentencia de fecha 8 julio de 2015, rol 1.579-2015.

Corte Suprema, sentencia de fecha 9 marzo de 2017, rol 70.829-2016.

Corte Suprema, sentencia de fecha 19 octubre de 2017, rol 40860-2017.

Corte Suprema, sentencia de fecha 7 noviembre de 2017, rol 11.486-2017.

Corte Suprema, sentencia de fecha 28 noviembre de 2017, rol 33.813-2017.

Corte Suprema, sentencia de fecha 6 junio de 2018, rol 44.656-2017.

Corte Suprema, sentencia de fecha 25 junio de 2018, rol 13.185-2018.

Corte Apelaciones Temuco, sentencia de fecha 27 julio de 2018, rol 618-2018.

Corte Apelaciones Punta Arenas, sentencia de fecha 23 agosto 2018, rol 158-2018.

Corte Suprema, sentencia de fecha 18 octubre de 2018, rol 39.368-2017.

Corte Suprema, sentencia de fecha 25 febrero de 2019, rol 12.852-2018.

Corte Apelaciones Concepción, sentencia de fecha 13 diciembre de 2019, rol 254-2019.

Corte Apelaciones San Miguel, sentencia de fecha 6 enero de 2020, rol 21-2020.

Corte Apelaciones Santiago, sentencia de fecha 6 enero de 2020, rol 63-2020.

Corte Apelaciones Punta Arenas, sentencia de fecha 6 marzo de 2020, rol 43-2020. 
